\title{
Two-dimensional study of heat transfer characteristics flow in a corrugated channel
}

\author{
R. Benchabi*, A. Lanani** \\ *LEAP Laboratory, Mechanical Engineering Department, Freres Mentouri University, Constantine, 25000, Algeria, \\ E-mail: rbenchabi@yahoo.fr \\ **MAM Laboratory, Mathematics Department, Freres Mentour University, Constantine, 25000, Algeria, \\ E-mail: alanani1@yahoo.fr
}

cross ${ }^{\text {ref }}$ http://dx.doi.org/10.5755/j01.mech.22.2.13321

\section{Introduction}

In industrial societies, the heat exchanger is an important component in energy management which much of the heat energy passes through. Heat exchangers have applications in the food industry, manufacturing, petrochemical, etc... Many heat exchangers in a variety of methods are equipped with exchange surface specifically designed to present a higher heat exchange coefficient and in particular higher than smooth surfaces. Among the used techniques in the design of the exchangers, the use of the corrugation provides increased turbulence and, thus, heat transfer. The objective of this study is to determine the influence of certain physical parameters of the thermal and hydraulic behavior using the Fluent CFD code. Many numerical and experimental research works have been conducted in this field in order to enhance the heat transfer in the heat exchangers.

A numerical study concerning the effect of Reynolds number on the flow and heat transfer in a triangularcorrugated channel for a range of Reynolds number varying from 400 to 1400 is given in [1]. A model of two equations was adopted for modeling turbulence. The authors found that the friction coefficient and the Nusselt number are influenced by the Reynolds number and that they are superior to those of the smooth channel.

In [2] the authors conducted an experimental study in a plate heat exchanger channel under two-phase flow conditions. The heat transfer coefficient has been measured in this case for several geometries of exchangers according to the air and water flow rates. The results showed that in all cases, the two-phase transfer coefficient is greater than that of the single-phase. The authors also verified from the flow visualization that the regime becomes turbulent for a Reynolds number greater than 650 .

Previous work was conducted by [3] in order to numerically study the effect of the corrugation angle and the aspect ratio $h / w$ of the three-dimensional flow and heat transfer in a triangular base channel simulating a corrugated plate heat exchanger. The RSM model was considered for modeling turbulence. Correlations are given to predict the Nusselt number and friction factor in such a wavy channel. The authors found that the friction coefficient and the Nusselt number are influenced by the Reynolds number and the geometrical parameters associated with the channel.

The effects of hydrodynamic conditions on improving the heat transfer for a single-phase flow in a wavy channel has been investigated in an experimental study [4]. The study is performed for a wide range of Reynolds num- ber $(0<R e<7500)$ in order to obtain the various flow regimes. The measured local temperatures are used to assess the local and overall heat transfer coefficient of the corrugated heat exchanger. The authors concluded that the heat transfer in corrugated channel is always higher than smooth channel.

A numerical study of laminar flow in a sinusoidal periodic channel was developed in [5]. The study is based on the finite difference method for a range of Reynolds number $\quad(10<R e<1000)$, various viscous liquids $(\operatorname{Pr}=5.35,150)$ and $\gamma$ aspect ratio $(0 \leq \gamma \leq 1)$. The authors found that the field flow is strongly influenced by the Reynolds number and aspect ratio. For low values of the Reynolds number and aspect ratio $((R e=10)$ and $(\gamma=0.25)$, the regime remains laminar; while for high values, the regime becomes turbulent and zones of recirculation appear and are increasingly large.

In his numerical study [6], Naphon considered a wavy channel with a constant heat flux imposed on the walls with three corrugations angles $20^{\circ} ; 40^{\circ}$ and $60^{\circ}$ and flow velocities of Reynolds number ranging from 400 to 1600 . The flow and heat transfer were simulated by the $k$ - $\varepsilon$ model and the finite volume method. From this study, the author finds that the Nusselt number increases with increasing Reynolds number and corrugation angle.

The study of Wang et al. [7] is devoted to study heat transfer of an unstable flow in periodic wavy passages. The authors found that the wavy passages bring no significant improvement of heat transfer when flow is stable. However, if the flow was unstable, significant increases in the order of 2.5 of heat exchange will be observed.

The effects of parameters related to the corrugated geometry and Reynolds number on the friction coefficient and the Nusselt number has been studied in [8]. The results showed that the latter increase with an increase in the Reynolds number and the amplitude-wavelenght ratio. The improved heat transfer is not significant for small ratio; however, it is for large Reynolds numbers. Zones of recirculation appear and the distance between the point of separation and reattachment increased with an increase in the ratio and the Reynolds numbers.

Experiments of forced convection were performed to determine the heat transfer and friction coefficient in a corrugated channel. Measurements were made for two different values of the channel height ( 5 and $10 \mathrm{~mm}$ ) and a corrugation angle of $\alpha=20^{\circ}$. Flow rates varying for a Reynolds number ranging from 1200 to 4000 . The authors found from this experiment that the increase in the height of the channel 
results in a substantial increase in the Nusselt number; secondly, when the height of the channel increases, the pressure gradient decreases but the friction coefficient increases [9].

An experimental comparison concerning the effect of the form of two corrugations; one curved and the other acute on the convective heat transfer of a corrugated channel has been made [10]. The results are obtained for a Reynolds number between 2,000 and 5,000; a corrugation angle of $30^{\circ}$ and a channel height of $5 \mathrm{~mm}$. The author concluded that the heat transfer performance to the curved shape is larger than those of the acute form.

A numerical and experimental study was conducted by [11] on convective heat transfer in a channel with a triangular wave uniform heat flux. The $k-\omega$ model is used for turbulence modeling in a range of Reynolds number varying from 500 to 5000. The authors have noticed numerically that as the Reynolds number increases, the Nusselt number inceases as well. They also established correlations based on the measured results by using the hot wire anemometer, to obtain the Nusselt number and the friction coefficient under the uniform heat flux condition.

The heat transfer and air flow pressure drop in corrugated triangular and sinusoidal channels, with uniform wall heat flux and a row of the Reynolds number ranging from 2000 to 9000 has been studied [12]. The author studied the effect of the corrugation angle, the height channel and the Reynolds number versus the heat transfer and pressure losses. It has been found that increasing the angle and the height results in an increased heat transfer.

Finally, a numerical study is devoted to the flow in a horizontal corrugated channel for both laminar and turbulent regimes [13]. The author noted that the friction coefficient is a function of the Reynolds number and it changes with the geometry (specifically when the step ratio varies from 3 to 4 ).

\section{Mathematical model}

This study concerns the analysis of a flow in a triangular corrugated channel. The geometric configuration is shown in Fig. 1.

The considered fluid (air) is incompressible ( $\rho=$ cste), Newtonian and has constant properties ( $\mu$ and $C_{p}$ constants).

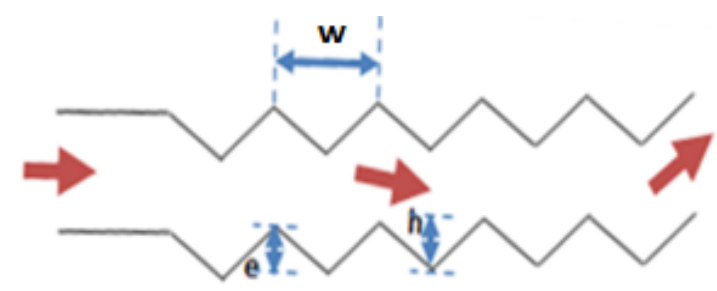

Fig. 1 The studied configuration

The flow is assumed two-dimensional and steady. The standard $k-\varepsilon$ model of turbulence is used to simulate momentum and heat transports.

The equations governing the flow and heat transfer can be written in the following form:

Equation of continuity:

$$
\frac{\partial}{\partial x_{i}}\left(\rho u_{i}\right)=0 \text {. }
$$

Equation of momentum conservation:

$$
\frac{\partial}{\partial x_{i}}\left(\rho u_{i} u_{j}\right)=-\frac{\partial \rho}{\partial x_{j}}+\frac{\partial}{\partial x_{i}}\left[\left(\mu_{t}+\mu\right) \frac{\partial u_{j}}{\partial x_{i}}\right] \text {. }
$$

Equation of energy:

$$
\frac{\partial}{\partial x_{i}}\left(\rho u_{i} T\right)=\frac{\partial}{\partial x_{i}}\left[\left(\frac{\mu_{t}}{\sigma_{t}}+\frac{\mu}{\sigma}\right) \frac{\partial T}{\partial x_{i}}\right] \text {. }
$$

The turbulent kinetic energy equation:

$$
\rho u_{i} \frac{\partial k}{\partial x_{i}}=\frac{\partial}{\partial x_{i}}\left[\left(\mu+\frac{\mu_{t}}{\sigma_{t}}\right) \frac{\partial k}{\partial x_{i}}\right]+G-\rho \varepsilon,
$$

where $\rho \varepsilon$ is the rate of destruction of $k ; G$ is the $k$ generation rate.

$$
G=\mu_{t}\left[\left(\frac{\partial u_{i}}{\partial x_{j}}+\frac{\partial u_{j}}{\partial x_{i}}\right) \frac{\partial u_{i}}{\partial x_{j}}\right]
$$

The rate of dissipation of turbulent kinetic energy equation is as follows:

$$
\rho u_{i} \frac{\partial \varepsilon}{\partial x_{i}}=\frac{\partial}{\partial x_{i}}\left[\left(\mu+\frac{\mu_{t}}{\sigma_{t}}\right) \frac{\partial \varepsilon}{\partial x_{i}}\right]+\frac{\varepsilon}{k}\left(C_{\varepsilon_{1}} G-C_{\varepsilon_{2}} \rho \varepsilon\right) .
$$

The empirical constants of the turbulence model are given in Table.

The empirical constants of the turbulence model

\begin{tabular}{|c|c|c|c|c|c|}
\hline $\begin{array}{c}\text { Cons- } \\
\text { tants }\end{array}$ & $C_{u}$ & $C_{\varepsilon_{1}}$ & $C_{\varepsilon_{2}}$ & $\sigma_{K}$ & $\sigma_{\varepsilon}$ \\
\hline Values & 0.09 & 1.44 & 1.92 & 1.0 & 1.3 \\
\hline
\end{tabular}

\section{Numerical procedure}

The above equations are discretized by virtue of the finite volumes numerical method. The elliptical nature of equations governing flow and heat transfer requires the knowledge of the boundary conditions to be defined over the entire computational domain. For accurate simulation of the flow channel, a channel of 14 corrugations is considered with a derived flow velocity of Reynolds number and a hot temperature imposed at the inlet section. On the walls of the channel, the conditions of no slip, impermeability and cold constant temperature at inlet are used. The pressure velocity coupling is treated by the SIMPLE Algorithm and the approximate solution is obtained by the T.D.M.A algorithm (Tri-Diagonal Matrix Algorithm). The second order upwind scheme is used to the discretization of the equations (convective terms) for the determination of a more stable and accurate solution of these equations.

Under a relaxation technique is applied for the control of the convergence of the iterative process which is achieved for a criterion of the maximum of the absolute values of normalized residuals across the computational domain $\left(\varepsilon<10^{-5}\right)$. 
To represent and analyze the heat transfer and the flow in the two-dimensional corrugated channel, the Reynolds number based on the hydraulic diameter, the friction coefficient and the Nusselt number are calculated as follows:

The Reynolds number:

$$
R e=\frac{\rho U D_{h}}{\mu} .
$$

The friction coefficient $\mathrm{f}$ is computed by using the formula:

$$
f=\frac{-\frac{d P}{d x} D_{h}}{\frac{1}{2} \rho V^{2}},
$$

where $\frac{d P}{d x}$ is the pressure gradient; $\rho$ is the density and $V$ is the average fluid velocity. equation:

The average Nusselt number is expressed by the

$$
N u=\frac{h D_{h}}{\lambda} .
$$

In order to obtain stable and precise solutions, the effect of the mesh on the solution was performed for different numbers of nodes. Four meshes were considered and presented as the local variation of the Nusselt number, velocity and temperature profiles for $R e=400$ with an aspect ratio $h / w=0.357$.

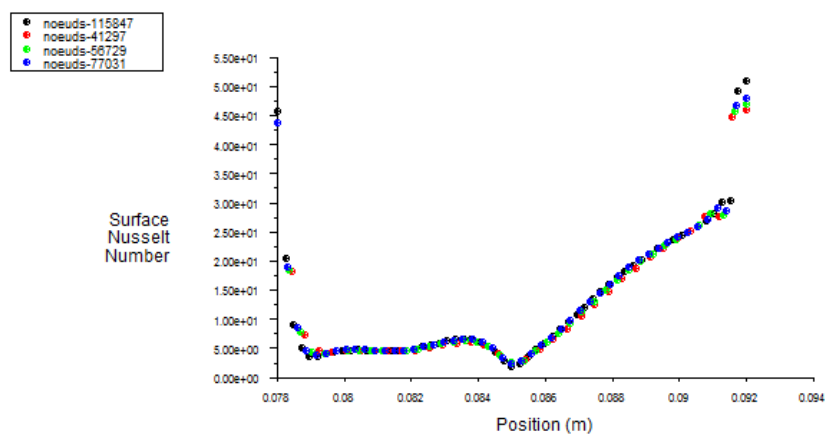

Fig. 2 Variation of local Nusselt number for $h / w=0.357$, $\operatorname{Re}=400$

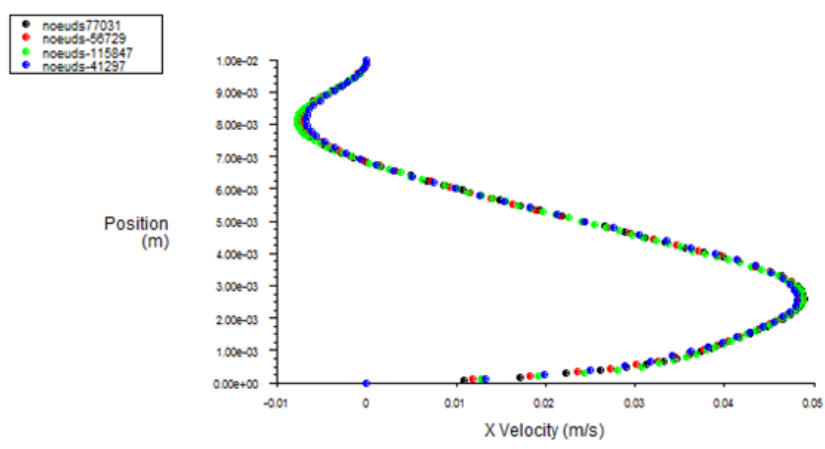

Fig. 3 Velocity profiles with $h / w=0.357, R e=400$

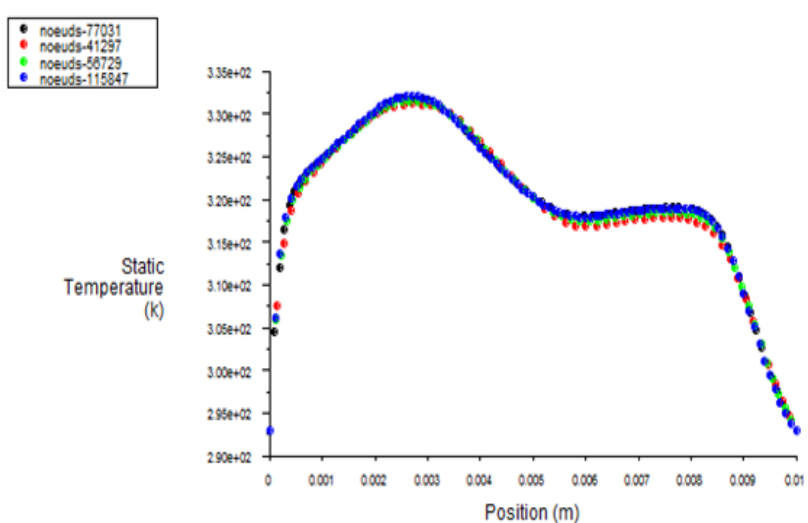

Fig. 4 Temperature profiles with $h / w=0.357, \operatorname{Re}=400$

Figs. 2-4 showed that the four meshes have an identical appearance. In order to save time, the considered mesh in the present study is 56729 .

\section{Results and discussion}

The variation in average Nusselt number as a function of the Reynolds number for the corrugated triangular channel with $h / w=0.357$ is shown in Fig. 5. We find that the Nusselt number is influenced by the Reynolds number. We also see that the increasing Reynolds increases the Nusselt and the Nusselt numbers of the corrugated channel are higher than those of the smooth channel. The numerical results obtained in this study are in good agreement with the experimental data of Vlasogiannis (2002).

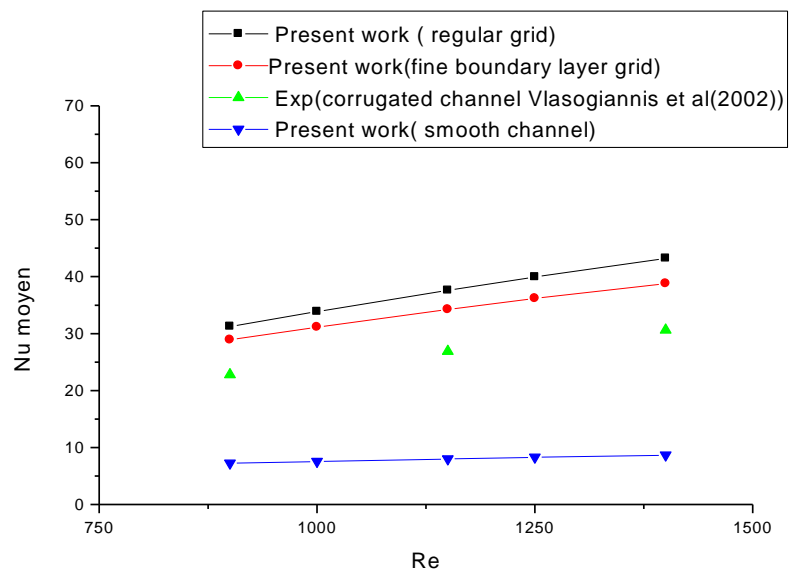

Fig. 5 Variation of average Nusselt number as a function of Reynolds with $h / w=0.357$

The graphical representation of the friction coefficient as a function of Reynolds with $h / w=0.357$ is given by Fig. 6 . It is seen that the friction decreases with increasing Reynolds and there is a good agreement between the numerical results obtained by the present simulation and those of the experiment conducted by Kanaris et al (2005). This figure also shows that the friction coefficients for the triangular corrugated channel are higher than those of the smooth channel.

Fig. 7 shows the contour of the average velocity for $R e=1400$ with $h / w=0.357$, there is shown a central flow with high velocities which decrease until it becomes zero near the solid walls, and satisfying the no-slip condition. Thick dynamic boundary layers are observed along the top 
wall corresponding to the dunes and along the bottom wall corresponding to the valleys where fluid velocities are low (decelerated fluid) and they are becoming thinner where velocities are important.

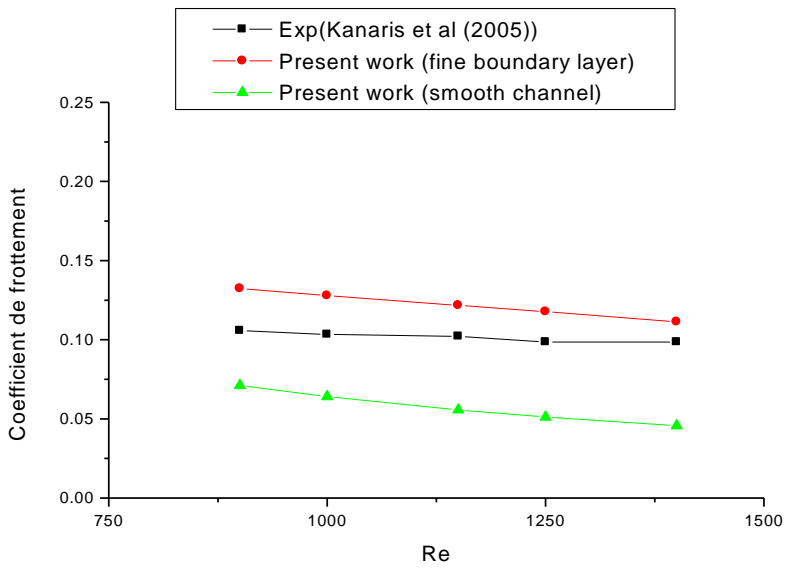

Fig. 6 Variation of friction coefficient versus Reynolds with $h / w=0.357$
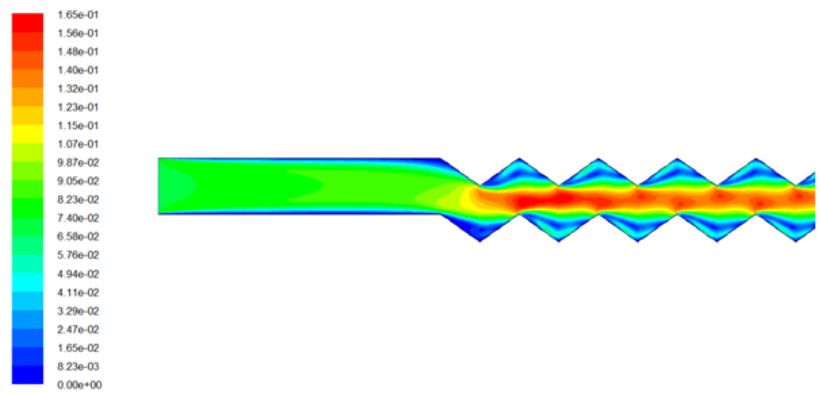

Fig. 7 Velocity contour with $h / w=0.357, R e=1400$

The streamlines contour with $h / w=0.357$ for $R e=1400$ is represented by the Fig. 8 . We note that the velocity quantities are maximal where the streamlines converge. The streamlines approximate increasingly corners where the fluid is accelerated, which causes detachment immediately downstream of these areas where appear zones of recirculation, the streamlines at these levels are moving away, so the velocity decreases.

Fig. 9 shows the velocity vectors for $R e=1400$ with $h / w=0.357$, it gives a good visualization of the evolution of the flow. We can easily notice a central flow with high velocity in the center of the triangular channel and the appearance of recirculation zones due to the change of fluid direction.

The profiles of the horizontal velocity for different Reynolds are plotted in Fig. 10, a, b with $h / w=0.357$
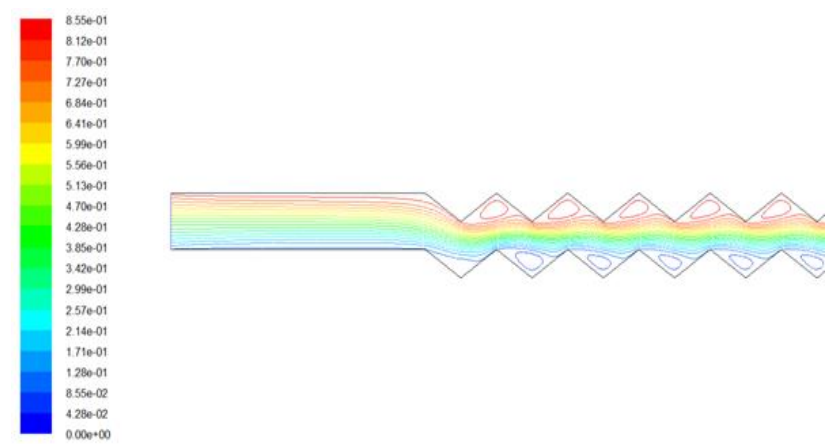

Fig. 8 Streamlines contour with $h / w=0.357, R e=1400$

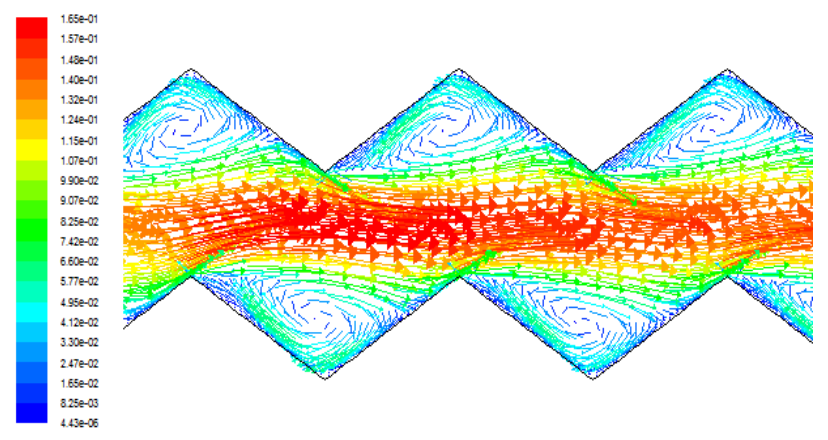

Fig. 9 Contour of the average velocity vectors with $h / w=0.357, \operatorname{Re}=1400$

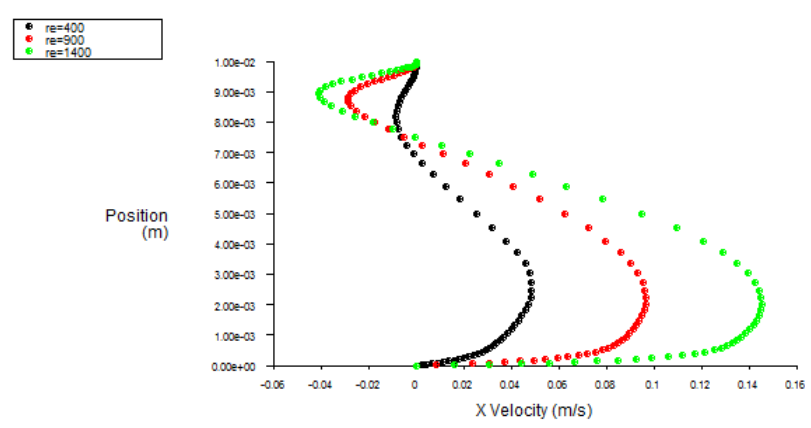

a
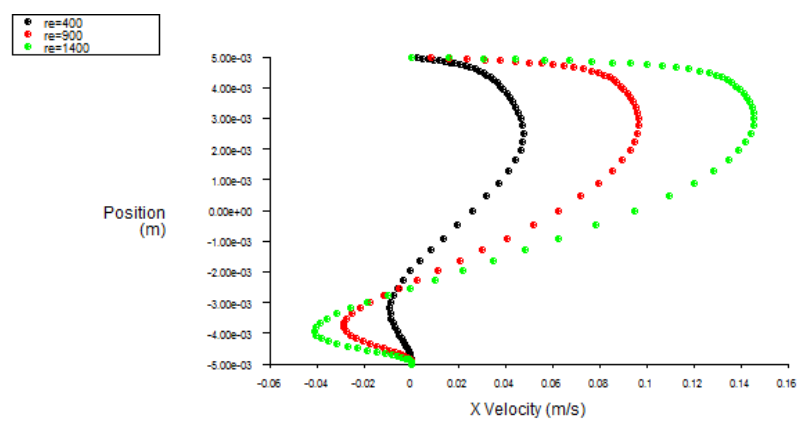

b

Fig. 10 Profiles of the horizontal component of the velocity with $h / w=0.357$ for different Reynolds: $\mathrm{a}-x=0.092 \mathrm{~m} ; \mathrm{b}-x=0.099 \mathrm{~m}$

corresponding to the vertices of the dunes and valleys of the upper and lower wall. These figures show the appearance of negative values of the velocity for different Reynolds numbers. This is due to the establishment of the recirculation zone. The area containing the negative velocity value increases with increasing Reynolds numbers.

Fig. 11 shows the pressure contours. It can be seen that the pressure upstream of the corrugated channel is more important, and the more we move away downstream, it becomes lower than that of the upstream. This highlights the pressure drop in the corrugated channel.

The Fig. 12 shows the temperature contours for $R e=1400$ with $h / w=0.357$.

We note that the temperatures are maximal at the entrance of the channel and that there is a heat transfer fluid to the cold walls of the channel. Thick thermal boundary layers are observed along the top wall corresponding to the dunes and along the bottom wall corresponding to the valleys. 


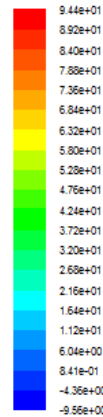

Fig. 11 Static pressure contour with $h / w=0.357$, $R e=1400$

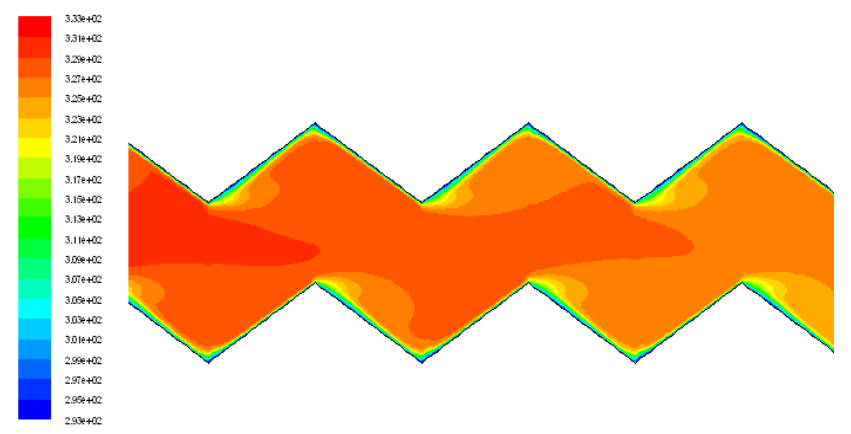

Fig. 12 Static temperature contour with $h / w=0.357$, $R e=1400$

corrugation

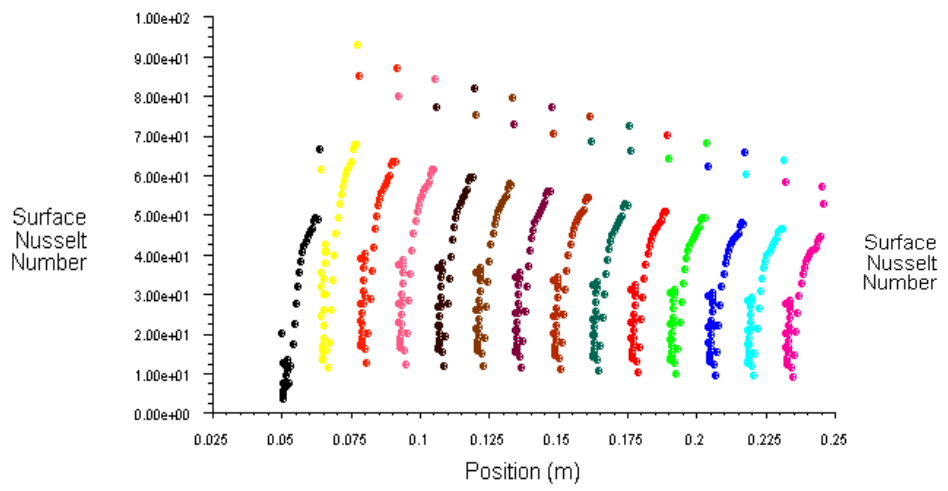

a

Fig. 14 Variation of the local a - lower wall; b - upper wall

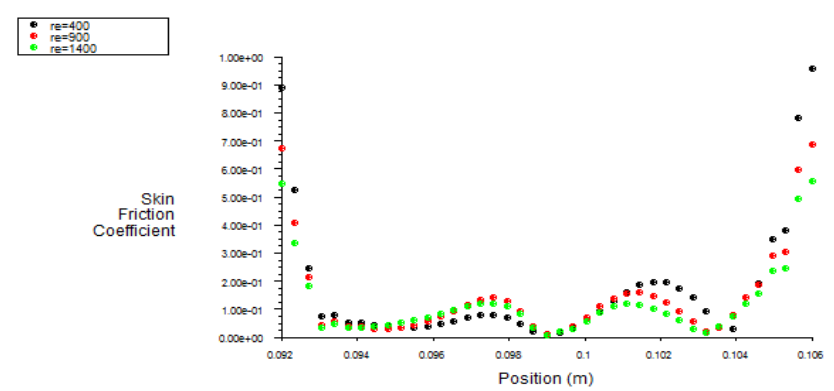

Fig. 15 Distribution of the local friction coefficient versus Reynolds with $h / w=0.357$ for periodic corrugation (lower wall)

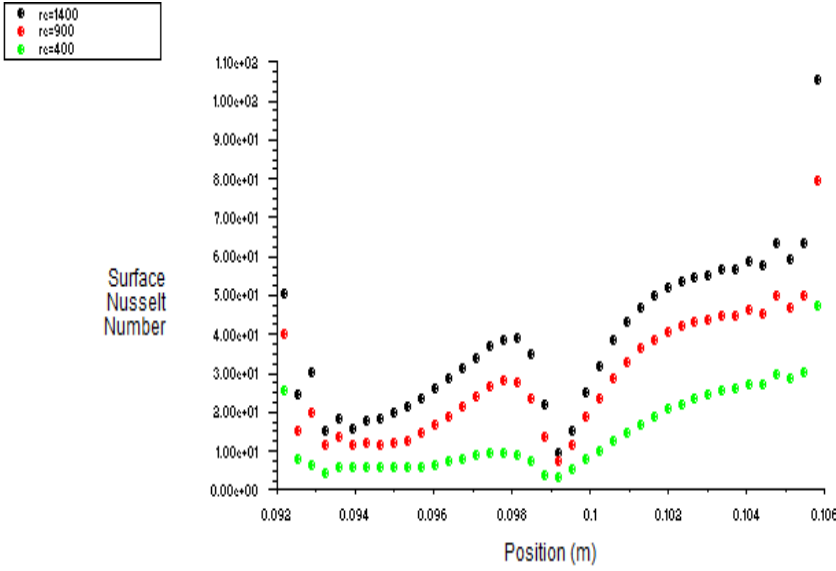

Fig. 13 Distribution of local Nusselt number as a function of Reynolds with $h / w=0.357$ for a periodic

This is in agreement with the thickening rate of the dynamic boundary layer in the fluid separation regions. The boundary layer is very thin in the attachment regions, which is consistent with the high velocity in these areas.

Fig. 13 shows the comparison of the local Nusselt number distributions as a function of Reynolds.

It is found that when the Reynolds number increases, the Nusselt number increases too.

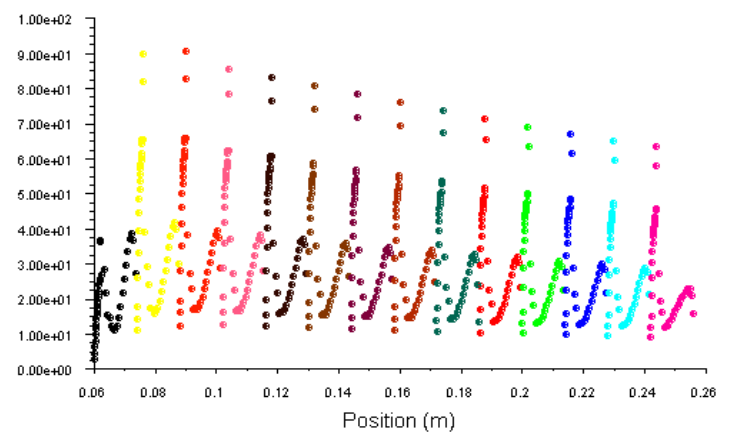

$\mathrm{b}$

with $h / w=0.357, \quad R e=1400$ for all corrugations: 


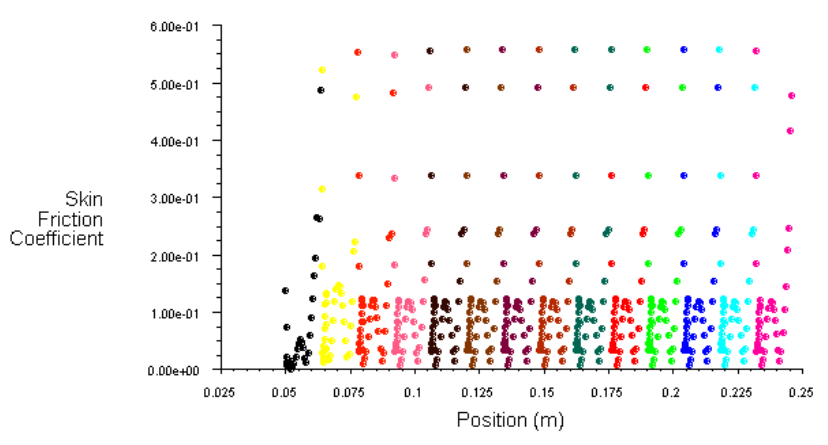

a

Fig. 16 Variation of the local friction coefficient a - lower wall; b - upper law

\section{Conclusions}

The study of two-dimensional incompressible turbulent flow with heat transfer in a channel simulating a corrugated plate heat exchanger is the subject of this numerical study. The numerical procedure for solving the equations governing the flow is based on the finite volume method. The results obtained numerically are in good agreement with experimental results available in the literature. In addition, this study allowed us to see the influence of the Reynolds number on the thermal and dynamic field and the heat transfer rate. Also, the results show that the local Nusselt number reaches maximum values in zones where velocity is important and in the zones corresponding to the reattachment points of fluid. The average Nusselt numbers increase with increasing Reynolds number and are better than those of the smooth channel. The friction coefficient decreases with increasing Reynolds number.

\section{References}

1. Kanaris, A.G.; Mouza, A.A.; Paras, S.V. 2005. Flow and heat transfer in narrow channels with corrugated walls a CFD Code Application, Chemical Engineering Research and Design 83(5): 460-468. http://dx.doi.org/10.1205/cherd.04162.

2. Vlasogiannis, P.; Karagiannis, G.; Argyropoulos, P.; Bontozoglou, V. 2002. Air-water two-phase flow and heat transfer in a plate heat exchanger, International Journal of Multiphase Flow 28: 757-772. http://dx.doi.org/10.1016/S -9322(02)00010-1

3. Kanaris, A.G.; Mouza, A.A.; Paras, S.V. 2009. Optimal design of a plate heat exchanger with undulated surfaces, International Journal of Thermal Sciences 48: 1184-1195. http://dx.doi.org/10.1016/j.ijthermalsci.2008.11.001.

4. Gradeck, M.; Hoareau, B.; Lebouche, M. 2005. Local analysis of heat transfer inside corrugated channel, International Journal of Heat and Mass Transfer 48: 19091915.

http://dx.doi.org/10.1016/j.ijheatmasstransfer.2004.12. 026.

5. Metwally, H.M.; Manglik, R.M. 2004. Enhanced heat transfer due to curvature-induced lateral vortices in lam-

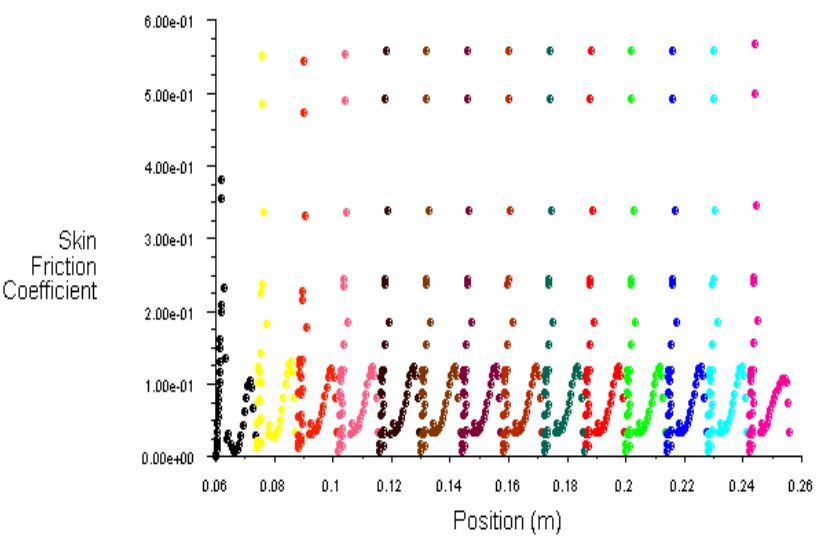

$\mathrm{b}$

with $h / w=0.357, \quad R e=1400$ for all corrugations:

inar flows in sinusoidal corrugated-plate channels, International Journal of Heat and Mass Transfer 47: 22832292.

http://dx.doi.org/10.1016/j.ijheatmasstransfer.2003.11.019.

6. Naphon, P. 2008. Effect of corrugated plates in an inphase arrangement on the heat transfer and flow developments, International Journal of Heat and Mass Transfer 51: 3963-3971.

http://dx.doi.org/10.1016/j.ijheatmasstransfer.2007.11.050.

7. Wang, G.; Vanka, S.P. 1995. Convection heat transfer in periodic wavy passages, International Journal of Heat and Mass Transfer 38(17): 3219-3230. http://dx.doi.org/10.1016/0017-9310(95)00051-A.

8. Wang, C.C.; Chen, C.K. 2002.Forced convection in a Wavy-Wall -Channel, International Journal of Heat and Mass Transfer 45: 2587-2595. http://dx.doi.org/10.1016/S0017-9310(01)00335-0.

9. Islamoglu, Y.; Parmaksizoglu, C. 2003. The effect of channel height on the enhanced heat transfer characteristics in a corrugated heat exchanger channel, Applied Thermal Engineering 23: 979-987. http://dx.doi.org/10.1016/S1359-4311(03)00029-2.

10. Islamoglu, Y. 2008. Effect of rounding of protruding edge on convection heat transfer in a converging-diverging channel, International Communications in Heat and Mass Transfer 35: 643-647.

http://dx.doi.org/10.1016/j.icheatmasstransfer.2007.11.002, MAY, 2008.

11. Zhang, L.Z.; Chen, Z. Y. 2011.Convective heat transfer in cross-corrugated triangular ducts under uniform heat flux boundary conditions, International Journal of Heat and Mass Transfer 54: 597-605.

http://dx.doi.org/10.1016/j.ijheatmasstransfer.2010.09.010.

12. Pehlivan, H. 2013. Experimental investigation of convection heat transfer in converging-diverging wall channels, International Journal of Heat and Mass Transfer 66: $128-138$.

http://dx.doi.org/10.1016/j.ijheatmasstransfer.2013.06.033.

13. Amano, R.S. 1985. A numerical study of laminar and turbulent heat transfer in a periodically corrugated wall channel, Journal of Heat Transfer 107: 564-569. http://dx.doi.org/10.1115/1.3247461. 
R. Benchabi, A. Lanani

TWO-DIMENSIONAL STUDY OH HEAT TRANSFER

CHARACTERISTICS FLOW IN A CORRUGATED

CHANNEL

S u m mary

The present work consists of a numerical study of turbulent incompressible two-dimensional flow with heat transfer in a corrugated channel using a computer code. The $\mathrm{k}-\varepsilon$ model is used for turbulence modeling. The governing continuity, momentum and energy equations are written in two-dimensional Cartesian coordinate system and are numerically solved using finite volume method. This study concerns the effect of the Reynolds number based on the hydraulic diameter and the thermal behavior of the hydraulic channel. The thermal and dynamic fields of the flow in the corrugated channel were obtained in a satisfactory manner. Satisfactory results about velocity distributions, pressure and temperature allowed us to understand the behavior of the Nusselt number and friction coefficient along the walls of corrugated channel. A comparison between the numerical and experimental results shows a good agreement.

Keywords: plate heat exchanger, corrugated channel, fluent, turbulence.

Received October 10, 2015

Accepted March 15, 2016 